\title{
Effect of method of preparation on hydrodesulphurization activity of Co- or Ni-promoted $\mathrm{MoS}_{2} / \mathrm{SBA}-15$ catalysts
}

\author{
SHELU GARG ${ }^{\mathrm{a}}$, KAPIL SONI ${ }^{\mathrm{a}}, \mathrm{V}$ V D N PRASAD ${ }^{\mathrm{a}}$, MANOJ KUMAR $^{\mathrm{a}}$, \\ THALLADA BHASKAR ${ }^{\mathrm{a}}, \mathrm{J}_{\text {K GUPTA }}^{\mathrm{a}}$, G MURALI DHAR ${ }^{\mathrm{b}, *}$ and C S GOPINATH ${ }^{\mathrm{c}}$ \\ ${ }^{a}$ CSIR-Indian Institute of Petroleum (IIP), Dehradun 248 005, India \\ ${ }^{b}$ Department of Chemical Engineering, GVP College of Engineering, \\ Madhurawada, Visakhapatnam 530 048, India \\ ${ }^{\mathrm{c}}$ Catalysis Division, CSIR-National Chemical Laboratory, Pune 411 008, India \\ e-mail: dhargm@gmail.com
}

MS received 15 September 2013; revised 24 November 2013; accepted 27 November 2013

\begin{abstract}
Ordered mesoporous material SBA-15 was synthesized and used as a support for the preparation of molybdenum sulphide catalysts through precipitation from homogeneous solution (PFHS) technique with the Mo content varying from 2-12 wt\%. The prepared catalysts were evaluated for thiophene hydrodesulphurization catalytic activities at $400^{\circ} \mathrm{C}$. Catalysts prepared through PFHS method resulted in highly dispersed $\mathrm{MoS}_{2}$ catalysts, which were inferred from powder X-ray diffraction (XRD), X-ray photoelectron spectroscopy (XPS), low temperature oxygen chemisorptions (LTOC) and BET surface area analysis. The relationship between XPS intensity ratio, oxygen chemisorption and catalytic activities is discussed in terms of highly dispersed nano particles of $\mathrm{MoS}_{2}$ and its consequence in accommodating more promoted atoms at the edge sites.
\end{abstract}

Keywords. PFHS method; $\mathrm{MoS}_{2}$; SBA-15; HDS; promotional effects.

\section{Introduction}

Environmental concerns about pollution by sulphur and nitrogen compounds and particulate matter, containing carcinogenic compounds has led to stringent specifications on petroleum products such as gasoline and diesel. Practical limitations of after-treatment devices in automobiles have shifted the responsibility of pollution control towards the petroleum refining industry. As a consequence, sulphur specifications of diesel were lowered to below $50 \mathrm{ppm}$. Most of the developed countries have sulphur specifications of diesel at around $10-15$ ppm. ${ }^{1-3}$ Feedstock preparation for onboard fuel cells requires sulphur levels to be brought down to $0.1 \mathrm{ppm}$. Hydrotreating is a well-known unit operation in a petroleum refinery to reduce sulphur levels in naphtha, kerosene, diesel, gas oil and residue..$^{1,2}$ In this process, employment of highly active catalysts is the most preferred choice among various options to reduce sulphur to ultra low levels. Calculations reveal that to reach such ultra low sulphur levels, activity of the catalysts needs to be increased by about seven times. ${ }^{2}$

Well-known commercial catalysts for hydrotreating operation contain Mo or $\mathrm{W}$ as active components, Co

\footnotetext{
*For correspondence
}

or $\mathrm{Ni}$ as promoters and $\gamma-\mathrm{Al}_{2} \mathrm{O}_{3}$ as support. ${ }^{1}$ Many approaches were followed to prepare highly active hydrodesulphurization (HDS) catalysts among which variation of support and variation of method of preparation were actively pursued. ${ }^{4,5}$ Rayo et al. ${ }^{6}$ studied the effect of the preparation method on the structural stability and hydrodesulphurization activity of NiMo/SBA15 catalysts. Effects of the acid and basic treatments on the stability of SBA-15 and NiMo/SBA-15 catalysts were evidenced by different characterization techniques and they observed that large deterioration of the SBA-15 structural order at basic $\mathrm{pH}$. Recent advances in the science and technology of ultra low sulphur diesel production including the effect of preparation methods for the highly active catalysts are available in a recent review. ${ }^{7}$ Klimova et al. ${ }^{8}$ and their group reported the highly active SBA-15 supported NiMo and CoMo catalysts and the role of citric acid. ${ }^{9,10}$ Various supports such as $\mathrm{TiO}_{2},{ }^{11,12} \mathrm{ZrO}_{2},{ }^{13}$ carbon, ${ }^{14}$ mixed oxides such as $\mathrm{TiO}_{2}-\mathrm{ZrO}_{2},{ }^{15} \mathrm{TiO}_{2}-\mathrm{Al}_{2} \mathrm{O}_{3},{ }^{16,17} \mathrm{MgO}-\mathrm{Al}_{2} \mathrm{O}_{3},{ }^{18}$ zeolites and mesoporous materials such as MCM-41, ${ }^{19-23}$ SBA-15, ${ }^{23-26}$ FSM-16, ${ }^{27} \mathrm{HMS},{ }^{28}$ KIT- $6,{ }^{29}$ and their metal-substituted or deposited analogues have been employed. ${ }^{30-32}$ These mesoporous materials exhibited outstanding activities for hydrodesulphurization functionality. In the earlier reports on $\gamma-\mathrm{Al}_{2} \mathrm{O}_{3}$-supported 
Mo catalysts prepared by precipitation from homogeneous solution (PFHS) method, several fold increase in activities were noted. ${ }^{33}$ In order to increase the activity of the SBA-15-supported systems further, we have used PFHS technique to deposit $\mathrm{MoS}_{2}$ nano particles inside the SBA-15 pore system. The preparation, characterization and discussion of hydrodesulphurization activities and its relation to physico-chemical properties of supported phase form the contents of this study.

\section{Experimental}

\subsection{Preparation, characterization and activity of catalysts}

SBA-15 was prepared by following the reported procedure using triblock polymer (P-123) as structure directing agent. ${ }^{34}$ The calcined materials and subsequently prepared catalysts were characterized by low angle Xray diffraction as well as wide angle XRD using GE XRD-6 diffractometer and micromeritics adsorptiondesorption unit (ASAP-2010).

The SBA-15-supported Mo catalysts were prepared by following precipitation from homogeneous solution method (PFHS). ${ }^{33-35} \mathrm{MoS}_{2} / \mathrm{SBA}-15$ catalyst was prepared by the PFHS method using thioacetamide as the precipitating agent. In a typical experiment, SBA-15 was suspended in a solution containing the required amount of ammonium molybdate, thioacetamide and nitric acid. The resulting mixture was heated to $90-95^{\circ} \mathrm{C}$ with constant stirring until the $\mathrm{MoS}_{2}$ was deposited on SBA-15 support. After the precipitation

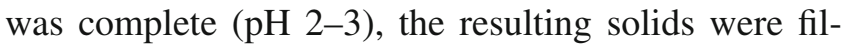
tered, washed and dried at $110^{\circ} \mathrm{C}$. The promoted catalysts were prepared by precipitation of cobalt sulphide or nickel sulphide on oven-dried $\mathrm{MoS}_{2} / \mathrm{SBA}-15$ catalyst. This was accomplished by suspending $\mathrm{MoS}_{2} / \mathrm{SBA}-$ 15 in a solution containing requisite amounts of urea, thioacetamide, nitric acid and cobalt or nickel nitrate and then heating the mixture on a water bath until completion of the precipitation at $\mathrm{pH} 7-9$. The resulting solids were filtered, washed and dried at $110^{\circ} \mathrm{C}$. Catalysts prepared by PFHS method are subjected directly to HDS. For comparison purpose, catalysts supported on SBA-15 were also prepared by conventional incipient wet impregnation method ${ }^{11}$ (IWIM). SBA-15 used for preparation of catalysts in both PFHS and IWIM methods are the same. The low temperature oxygen chemisorptions (LTOC) measurements were made on sulphided catalysts at $-78^{\circ} \mathrm{C}$ in a conventional volumetric adsorption unit with a provision to sulphide the catalysts in situ, according to a procedure described earlier. ${ }^{35}$ BET surface area and pore size distributions were carried out using ASAP-2010 pore analyser from micromeritics (USA). A vacuum generator ESCALAB/MK11 spectrometer with $\mathrm{Mg} \mathrm{K} \alpha$ radiation $(1253.6 \mathrm{eV})$ was used at $10^{-8}$ torr pressure along with Apple 11e (48 KB) micro computer for evaluating $\mathrm{Mo}$ and Si peak intensities. Binding energies are referenced against contaminant carbon present $(284.6 \mathrm{eV})$. Thiophene HDS activities were carried out at $400^{\circ} \mathrm{C}$ on catalysts sulphided at $400^{\circ} \mathrm{C}$ for $2 \mathrm{~h}$ in a fixed bed reactor operating at atmospheric pressure. ${ }^{26,30}$. Briefly, about $0.2 \mathrm{~g}$ of catalyst sample was secured between two plugs of quartz wool inside a microreactor (Pyrex glass tube, $0.8 \mathrm{~cm}$ I.D.). Prior to activity measurements, catalysts were sulphided at $400^{\circ} \mathrm{C}$ for $2 \mathrm{~h}$ with $\mathrm{CS}_{2}(43.6 \mathrm{~mol} \%) / \mathrm{H}_{2}\left(40 \mathrm{~cm}^{3} / \mathrm{min}\right)$. After sulphidation, thiophene HDS or cyclohexene hydrogenation (HYD) was conducted at $400^{\circ} \mathrm{C}$ with about $40 \mathrm{~cm}^{3} / \mathrm{min}$ of hydrogen previously saturated in a saturator containing the corresponding reactant feed at room temperature, that is, $10.7 \mathrm{~mol} \%$ of thiophene.

\section{Result and discussion}

\subsection{Support and catalyst characterization}

The support samples synthesized and calcined at $550^{\circ} \mathrm{C}$ for $6 \mathrm{~h}$ were used to prepare $\mathrm{MoS}_{2}$-supported catalysts by PFHS. The low angle XRD patterns of SBA-15 support, $8 \mathrm{wt} \% \mathrm{MoS}_{2} / \mathrm{SBA}-15,10 \mathrm{wt} \% \mathrm{MoS}_{2} / \mathrm{SBA}-15$ are shown in the figure 1 . It can be seen that the XRD pattern consists of a sharp low angle line corresponding to (100) reflection characterized by $d=103.8 \AA$ followed by two lines of low intensity corresponding to 110 characterized by $d=56.4 \AA$ and another reflection on the high angle side, corresponding to 200 reflection characterized by $d=27.7 \AA .{ }^{34}$ These three lines are characteristic of hexagonal mesoporous SBA-15 structure. It can be also be seen from figure 1 that the threepeak pattern is also exhibited by $8 \mathrm{wt} \% \mathrm{MoS}_{2} / \mathrm{SBA}-15$ as well as $10 \mathrm{wt} \% \mathrm{MoS}_{2}$ indicating that $\mathrm{MoS}_{2}$ deposition by PFHS technique did not cause any changes in the ordered mesoporous structure. However the $\mathrm{MoS}_{2}$ supported catalysts showed lower intensity for the 100 reflection compared to pure SBA-15. The wide angle Xray diffraction patterns of catalysts containing various amounts (2-12 wt \%) $\mathrm{MoS}_{2}$ on SBA-15 are presented in figure 2 . There is no evidence for the presence of crystalline $\mathrm{MoS}_{2}$ in all the patterns. This observation suggests that the $\mathrm{MoS}_{2}$ is in a highly dispersed state and the crystallite size of $\mathrm{MoS}_{2}$ is less than $4.0 \mathrm{~nm}$. The observation also indicates that the PFHS technique resulted 


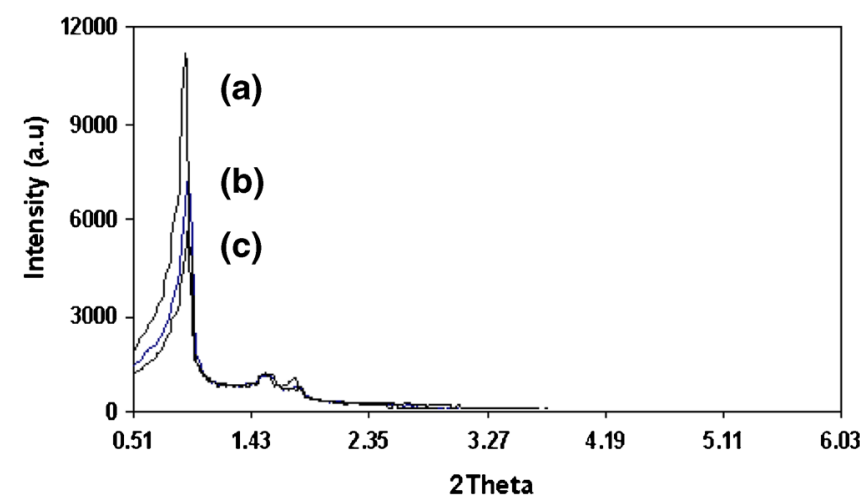

Figure 1. Low angle XRD pattern of (a) SBA-15, (b) $8 \%$ $\mathrm{MoS}_{2}-\mathrm{SBA}-15$ and (c) $10 \% \mathrm{MoS}_{2}-\mathrm{SBA}-15$.

in depositing highly dispersed nano particles of $\mathrm{MoS}_{2}$ inside the pores of SBA-15. The Ni-as well as Copromoted $\mathrm{MoS}_{2} / \mathrm{SBA}-15$ catalysts were also examined by wide angle XRD. Results related to Ni-promoted catalysts are shown in figure 3 . It can be noticed in these XRD patterns that there is no evidence for any crystalline phases of cobalt sulphide, nickel sulphide or compounds of promoter atoms and $\mathrm{MoS}_{2}$ phase.

The pure SBA-15 and $\mathrm{MoS}_{2} / \mathrm{SBA}-15$ catalysts were examined by BJH pore size analysis. Surface area of SBA-15 support is $650 \mathrm{~m}^{2} / \mathrm{g}$. Corresponding adsorption-desorption isotherms for SBA-15 (A) $8 \mathrm{wt} \% \mathrm{MoS}_{2} / \mathrm{SBA}-15$ (B) $10 \mathrm{wt} \% \mathrm{MoS}_{2} / \mathrm{SBA}-15$ (C) are shown in figure 4 . It can be noted that a $\mathrm{H}_{1}$ hysteresis loop in the range $P / P_{\mathrm{o}} 0.6-0.8$ is obtained in all the three cases. The pore size is about $66.3 \AA$. These results indicated that a narrow cylindrical pore size distribution, a characteristic of ordered hexagonal mesoporous SBA-15, is retained even after loading $10 \mathrm{wt} \% \mathrm{MoS}_{2}$ into the SBA-15 pores. It can also be seen that there is a small decrease in the width of hysteresis loop, indicating a decrease in pore volume and pore diameter after loading $\mathrm{MoS}_{2}$. Landau et al. ${ }^{36}$ analysed the surface area

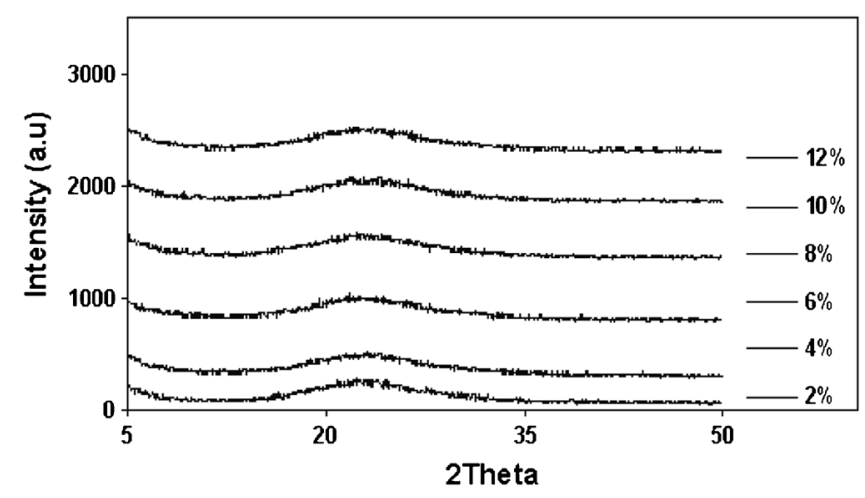

Figure 2. Wide angle XRD pattern of (2-12 wt $\%) \mathrm{MoS}_{2}$ supported on SBA-15.

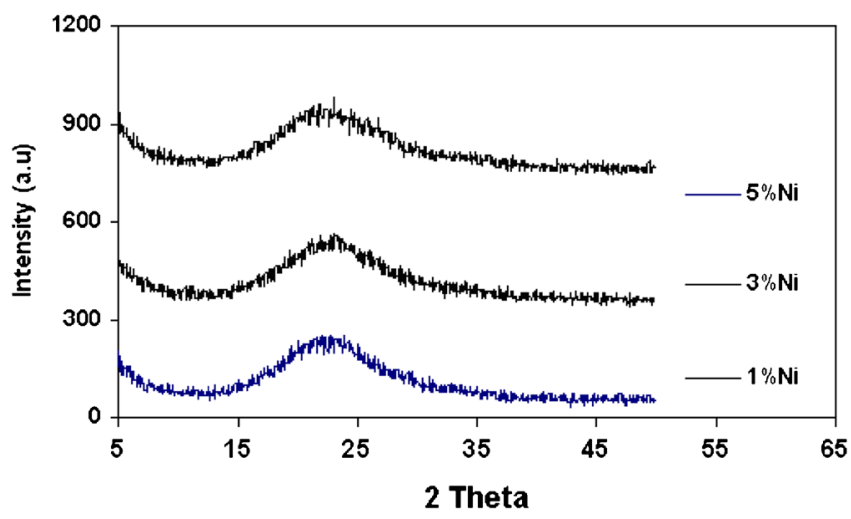

Figure 3. Wide angle XRD pattern of (1-5 wt\%) Ni promoted $10 \% \mathrm{MoS}_{2}-\mathrm{SBA}-15$ catalysts.

data in the case of thin layer of a metal sulphide species deposited in mesoporous materials, to suggest that normalized surface area of 0.9 indicates high dispersion of the sulphide phase inside SBA-15 pores. In the case of $10 \mathrm{wt} \% \mathrm{MoS}_{2} / \mathrm{SBA}-15$, the normalized surface area is found to be 0.9 indicating a high dispersion of $\mathrm{MoS}_{2}$ inside the SBA-15, pores up to that loading.

The BET surface areas of various catalysts as a function of $\mathrm{MoS}_{2}$ loading are shown in table 1 . The surface areas are very high and remain very high up to $10 \mathrm{wt} \%$ loading. However, at $12 \mathrm{wt} \%$ loading the surface area decreases considerably. The BET surface area data can be further analysed to obtain information about dispersion of the supported phase as a monolayer. For this purpose, the surface area for gram of support is calculated from surface area for gram of catalyst obtained from BET measurement. In the case of formation of monolayer, the surface area per gram of support remains constant with $\mathrm{MoS}_{2}$ loading while the surface area per gram of catalyst decreases. ${ }^{26}$ A plot of BET surface area per gram of catalyst as well as support is shown in figure 5 as a function of $\mathrm{MoS}_{2}$ loading. It can be seen that the surface area per gram of catalyst

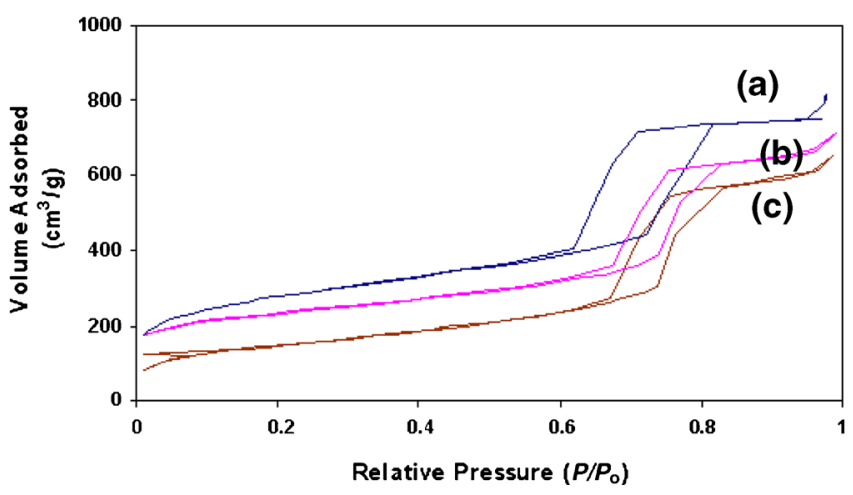

Figure 4. $\mathrm{N}_{2}$ adsorption-desorption isotherm of (a) SBA15, (b) $8 \mathrm{wt} \%$ Mo-SBA-15 and (c) $10 \mathrm{wt} \%$ Mo-SBA-15. 


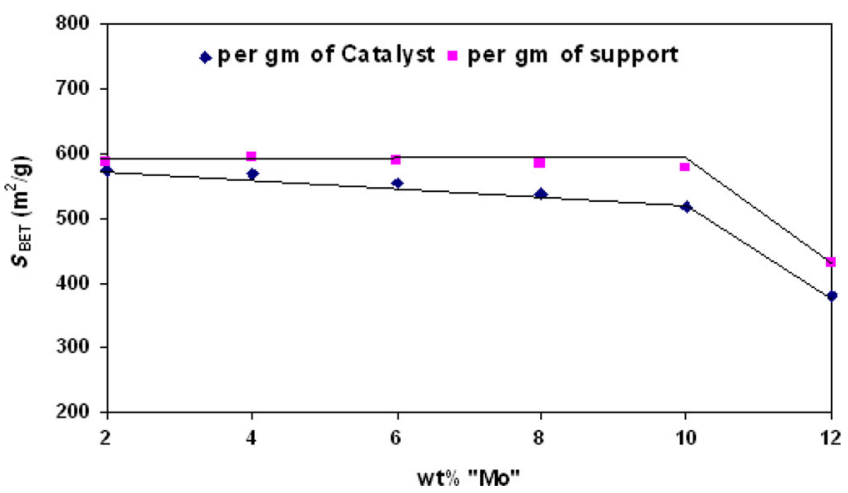

Figure 5. Variation of surface area of SBA-15-supported catalysts with Mo loading.

decreases while the surface area per gram of support remains more are less constant up to $10 \mathrm{wt} \%$ loading and the surface area per gram of support shows a drastic decrease at $12 \mathrm{wt} \%$ loading indicating a deviation from the monolayer behaviour. These results indicate that the $\mathrm{MoS}_{2}$ loading into SBA-15 by PFHS method results in very highly dispersed $\mathrm{MoS}_{2}$ which is probably present as a monolayer up to $10 \mathrm{wt} \%$ Mo loading. ${ }^{37}$ Landau et al. ${ }^{36}$ made similar surface area analysis in terms of normalized surface area (NSA) for a number of oxides. In a similar analysis of this case, a NSA of 0.9 is obtained which suggests that the $\mathrm{MoS}_{2}$ is well-dispersed in SBA-15 pores.

XPS-binding energies and intensity ratios provide useful information about valence state and dispersion of supported phase. Samples containing various amounts of $\mathrm{MoS}_{2}$ supported on SBA-15 by PFHS technique were examined by X-ray photo electron spectroscopy (XPS). The Si $2 p$ and Mo 3d line binding energies indicated that oxidation state of Mo on the surface of SBA-15 is $\mathrm{Mo}^{4+}$ species. From the intensities of the lines divided by their respective photo electron cross-sections, intensity ratios of $I_{\mathrm{Mo}} / I_{\mathrm{Si}}$ were calculated. The $I_{\mathrm{Mo}} / I_{\mathrm{Si}}$ ratios

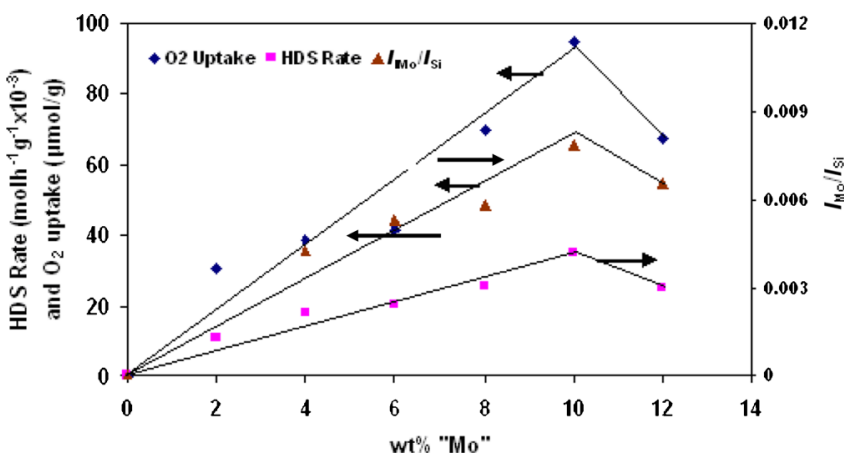

Figure 6. Variation of oxygen uptake, HDS rate and $I_{\mathrm{Mo}} / I_{\mathrm{Si}}$ with wt $\% \mathrm{MoS}_{2}$ loading.

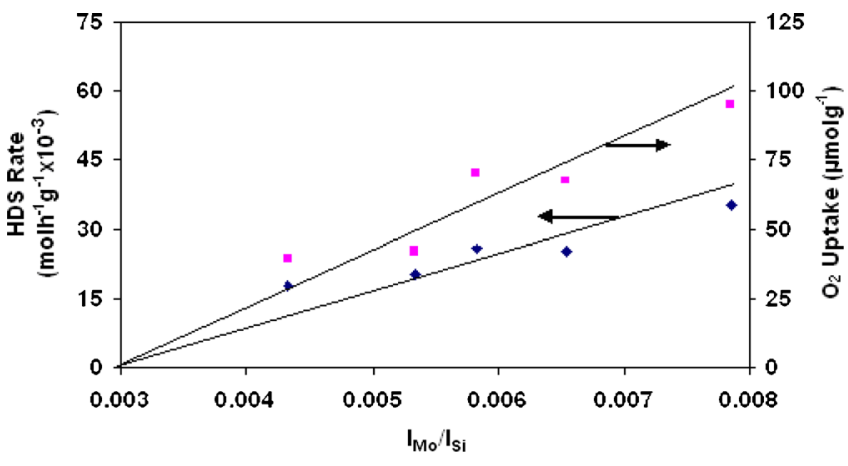

Figure 7. Correlation of XPS intensity ratios ESCA with HDS activity and $\mathrm{O}_{2}$ uptake of various wt $\% \mathrm{MoS}_{2}$ supported on SBA-15.

as mentioned earlier are a measure of dispersion of supported phase. The $I_{\mathrm{Mo}} / I_{\mathrm{Si}}$ ratios as a function of $\mathrm{MoS}_{2}$ loading are plotted in figure 6 . It can be seen that this ratio increases more or less linearly up to $10 \mathrm{wt} \% \mathrm{MoS}_{2}$ loading and then decreases at the highest loading studied (12 wt \%), indicating that the dispersion of molybdenum sulphide phase increases up to $10 \mathrm{wt} \%$ and then decreases. This result is similar to the conclusion arrived by surface area analysis as discussed earlier.

Oxygen chemisorption at $-78^{\circ} \mathrm{C}$ was carried out on sulphided $\mathrm{MoS}_{2} / \mathrm{SBA}-15$ containing 2-12 wt $\% \mathrm{MoS}_{2}$. The oxygen uptakes are shown in table 1 as a function of $\mathrm{MoS}_{2}$ loading and corresponding graphical representation is shown in figure 6 . It can be seen that the oxygen chemisorption increases linearly up to $10 \mathrm{wt} \% \mathrm{MoS}_{2}$ and then decreases beyond this point. It is well-known that oxygen uptake represents $\mathrm{MoS}_{2}$ dispersion or number of anion vacancies which are the seat of catalytic activity of supported catalysts. ${ }^{26}$

$\mathrm{O}_{2}$ uptake data can be used to derive useful information about $\mathrm{MoS}_{2}$ dispersion (O/Mo), equivalent molybdenum sulphide area (EMSA), surface coverage and crystallite size. This information calculated using oxygen uptake is shown in table 1 . It can be noticed that

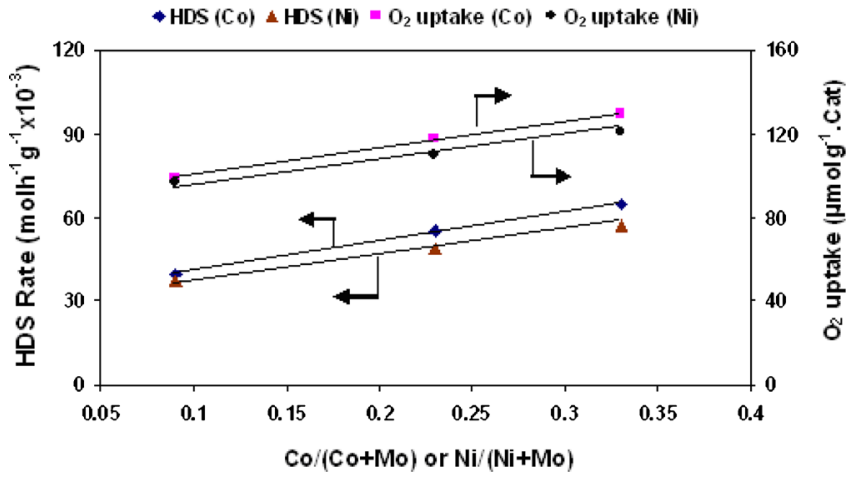

Figure 8. Promotional effect of $\mathrm{Co}$ and $\mathrm{Ni}$ on HDS of $10 \mathrm{wt} \% \mathrm{MoS}_{2} / \mathrm{SBA}-15$ catalysts. 


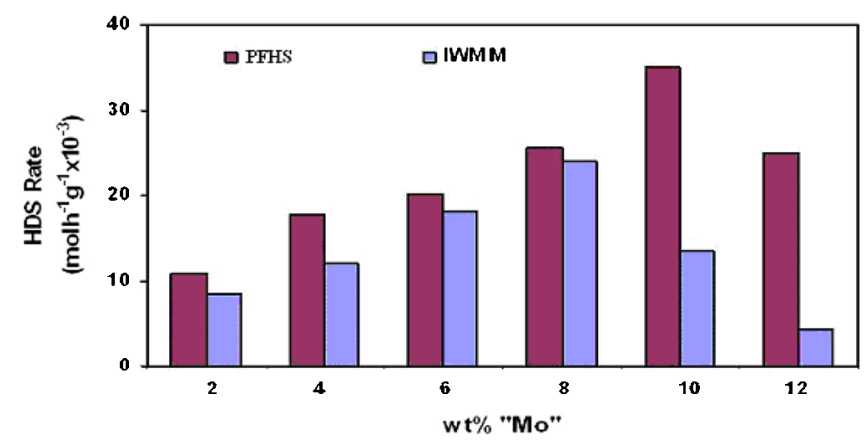

Figure 9. Comparison of HDS activity of $\mathrm{MoS}_{2}$ catalysts prepared by PFHS and IWIM.

EMSA and surface coverage increases up to $10 \mathrm{wt} \%$ $\mathrm{MoS}_{2}$ and the crystallite size varies in a narrow range around $2 \mathrm{~nm}$ up to $10 \mathrm{wt} \% \mathrm{MoS}_{2}$. The same parameter (crystallite size) shows a rapid increase but is still below the detection limit of XRD as shown in figure 2. In the same figure, a comparison is made with catalysts prepared by incipient wetness impregnation method (IWIM). It can be seen that the crystallite growth is rapid beyond $8 \mathrm{wt} \% \mathrm{MoS}_{2}$ loading for IWIM and $10 \mathrm{wt} \% \mathrm{MoS}_{2}$ loading for PFHS-derived catalysts. The crystallite size for PFHS-prepared $10 \mathrm{wt} \% \mathrm{MoS}_{2}$ catalyst is nearly half of that of IWIM. It can also be seen that the value for surface coverage for $10 \mathrm{wt} \%$ $\mathrm{MoS}_{2}$ is only $10.2 \%$ which indicates that the $\mathrm{MoS}_{2}$ selectively interacts with certain preferred sites on the surface of SBA-15. In other words, $\mathrm{MoS}_{2}$ distributes on the surface as monolayer patches possibly using certain energetically suitable hydroxyl groups on the surface. Fixing of Mo or $\mathrm{W}$ on oxide surfaces using hydroxyl groups on oxide surfaces is well-known. ${ }^{38,39}$

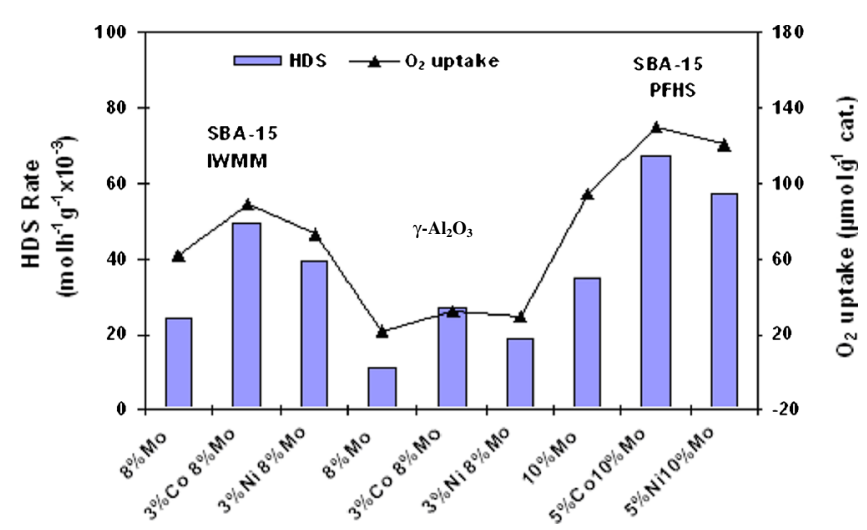

Figure 10. Comparison of HDS activity and $\mathrm{O}_{2}$ uptake of Mo, CoMo and NiMo catalysts supported on SBA-15 and $\gamma-\mathrm{Al}_{2} \mathrm{O}_{3}$.

\subsection{Catalytic activity studies}

Thiophene hydrodesulphurization is a well-known reaction for assessing the efficiency of sulphide catalysts for $\mathrm{C}-\mathrm{S}$ bond cleavage in heterocyclic sulphur molecules. In this investigation, hydrodesulphurization of thiophene was carried out at $400^{\circ} \mathrm{C}$ at atmospheric pressure on catalysts sulphided at $400^{\circ} \mathrm{C}$. The calculated reaction rates are shown as a measure of the activity and are shown in figure 6 as a function of $\mathrm{MoS}_{2}$ loading. It can be noticed that the HDS activity increases linearly up to $10 \mathrm{wt} \% \mathrm{MoS}_{2}$ loading beyond which the activity shows a decline. This observation is interesting in the light of XPS and oxygen chemisorption results which showed a similar increase up to $10 \mathrm{wt} \% \mathrm{MoS}_{2}$ loading and then shows a declining trend. Since XPS intensity ratios as well as oxygen chemisorption represent dispersion of $\mathrm{MoS}_{2}$, it is clear that the activity increases up to $10 \mathrm{wt} \%$ and declines beyond this point due to variation of active sites, namely anion vacancies. This relationship can be clearly seen in figure 7, where both HDS and oxygen uptakes are plotted as a function of XPS intensity ratios. A good linear correlation is obtained between $I_{\mathrm{Mo}} / I_{\mathrm{Si}}$ and HDS or oxygen uptakes emphasizes the excellent relationship between the three parameters intimately connected to the dispersion of $\mathrm{MoS}_{2}$.

\subsection{Promotional effect}

Cobalt and nickel are well-known promoters of Mo hydrodesulphurization catalysts. The effect of PFHS method on the promotional effect is studied in detail. In this investigation, $\mathrm{Co}$ and $\mathrm{Ni}$ catalysts containing 1 , 3 and $5 \mathrm{wt} \%$ were prepared by PFHS method and corresponding IWIM catalysts are also used. Thiophene HDS activity was measured in the sulphided state at $400^{\circ} \mathrm{C}$. Results of this measurement as a function of promoter content can be seen in figure 8 . The rate of reaction, BET surface areas and oxygen uptakes are shown in table 2. It can be seen that the HDS rate as shown in figure 8 increases up to highest composition studied on Co as well as Ni catalysts. The oxygen uptake also shows a similar trend of variation in both $\mathrm{Co}$ and $\mathrm{Ni}$ catalysts, indicating that the increased promotional effect is due to increased dispersion of molybdenum sulphide which allows more promoter atoms to be incorporated at the sulphur edge of molybdenum sulphide crystallites. Recent STM and DFT studies by Topsoe et al. ${ }^{40}$ showed that sulphur edge of hexagonal prism of $\mathrm{MoS}_{2}$ is the position preferentially occupied by promoter atoms, which undergoes morphological changes as a result of promoter atom incorporation. Therefore, it appears that the role of PFHS method is in 
Table 1. Physico-chemical characterization of $\mathrm{MoS}_{2} / \mathrm{SBA}-15$.

\begin{tabular}{lccccccc}
\hline wt\% "Mo" & $\begin{array}{c}\mathrm{SA}_{\mathrm{BET}} \\
\left(\mathrm{m}^{2} / \mathrm{g}\right)\end{array}$ & $\begin{array}{c}\mathrm{O}_{2} \text { uptake } \\
\left(\mu \mathrm{molg}^{-1}\right)\end{array}$ & $\begin{array}{c}\text { EMSA } \\
\left(\mathrm{m}^{2} / \mathrm{g}\right)^{\mathrm{a}}\end{array}$ & $\begin{array}{c}\mathrm{O} / \mathrm{Mo} \times 100 \\
(\%)\end{array}$ & $\begin{array}{c}\text { \%Surface } \\
\text { coverage }^{\mathrm{b}}\end{array}$ & \multicolumn{2}{c}{ Crystallite size $(\AA)^{\mathrm{c}}$} \\
\hline 2 & 574 & 30.7 & 17.3 & 29.4 & 2.9 & 12.0 & 13.7 \\
4 & 569 & 38.6 & 21.9 & 18.5 & 3.8 & 19.0 & 19.7 \\
6 & 554 & 41.5 & 27.5 & 15.3 & 4.9 & 22.8 & 23.2 \\
8 & 537 & 69.9 & 39.6 & 16.8 & 7.3 & 21.0 & 23.6 \\
10 & 518 & 94.8 & 53.7 & 18.2 & 10.2 & 19.4 & 37.1 \\
12 & 380 & 67.4 & 34.8 & 10.8 & 9.9 & 35.9 & 50.5 \\
\hline
\end{tabular}

${ }^{a}$ EMSA (equivalent $\mathrm{MoS}_{2}$ area), calculated using a factor 0.56616 obtained from pure $\mathrm{MoS}_{2}$ BET surface area divided by oxygen uptake

$\mathrm{b}($ EMSA/BET surface area) $\times 100$

${ }^{\mathrm{c}} 5 \times 10^{4} / \rho M$, where $\rho$ is the density of $\mathrm{MoS}_{2}\left(4.8 \mathrm{~g} / \mathrm{cm}^{3}\right)$ and $M$ is EMSA $/ \mathrm{g}$ of $\mathrm{MoS}_{2}$

${ }^{\mathrm{d}}$ Crystallite size of catalyst from incipient wet impregnation (IWIM)

preparing $\mathrm{MoS}_{2}$ nano particles and subsequent effective incorporation of promoter atoms at the edge positions. It is well-known that in the case of IWIM prepared catalysts, a maximum occurs for both HDS and oxygen uptakes at $3 \mathrm{wt} \%$ promoter atoms. ${ }^{1}$ Even at $5 \mathrm{wt} \%$, in case of PFHS catalysts, the activity is still increasing and so does oxygen uptake. This clearly demonstrates that high $\mathrm{MoS}_{2}$ dispersion provides more sulphur edges to accommodate larger number of promoter atoms at the edge positions.

\subsection{Comparison of $\mathrm{MoS}_{2} / \mathrm{SBA}-15$ preparation by PFHS and IWIM methods}

In order to assess the advantage of the PFHS method with reference to IWIM, a comparison is drawn in table 2, where $\mathrm{MoS}_{2}$ catalysts and their promoted analogues are compared with respect to activities and oxygen uptakes. It can be seen that from the data given on SBA-15 prepared by the two methods that the dispersion as measured by oxygen uptakes can be increased by $30-40 \%$ by this novel preparation method. In comparison with $\gamma-\mathrm{Al}_{2} \mathrm{O}_{3}$-supported catalysts prepared by IWIM, the dispersion is increased by four times on Mo/SBA-15 catalysts prepared by PFHS method. A similar comparison of activity parameters shown in table 2 indicates that about three times more active catalysts can be prepared by combination of SBA-15 support and PFHS preparation method.

A comparison of PFHS prepared catalysts can be better appreciated by plotting the activities of the catalysts in the same graph as a function of molybdenum loading as shown in figure 9. It can be noticed that the entire wt $\%$ of $\mathrm{MoS}_{2}$-loading PFHS catalysts shows superior activities for thiophene hydrodesulphurization. The superiority of the catalysts is more striking at higher loadings namely at $10 \mathrm{wt} \% \mathrm{MoS}_{2}$ and $12 \mathrm{wt} \%$ $\mathrm{MoS}_{2}$. At $10 \mathrm{wt} \% \mathrm{MoS}_{2}$ loading, the activity is more than doubled. Similar observation is also made in the case of oxygen uptake and the crystallite size calculated for $10 \mathrm{wt} \% \mathrm{MoS}_{2}$ which is half of IWIM catalysts (table 1) showing that PFHS method results in high dispersion even at high $\mathrm{MoS}_{2}$ loading. This high dispersion also allows accommodation of more promoter

Table 2. Characterization and catalytic activity of supported Mo, CoMo and NiMo catalysts.

\begin{tabular}{|c|c|c|c|}
\hline Catalysts & $\mathrm{SA}_{\mathrm{BET}}\left(\mathrm{m}^{2} / \mathrm{g}\right)$ & $\mathrm{O}_{2}$ uptake $\left(\mu \mathrm{molg}^{-1}\right)$ & HDS Rate $\left(\mathrm{molh}^{-1} \mathrm{~g}^{-1} \times 10^{-3}\right)$ \\
\hline \multicolumn{4}{|l|}{ PFHS } \\
\hline $10 \% \mathrm{Mo} / \mathrm{SBA}-15$ & 525 & 94.8 & 35.0 \\
\hline $5 \%$ Co $10 \%$ Mo/SBA- 15 & 425 & 129.5 & 67.6 \\
\hline $5 \% \mathrm{Ni} 10 \% \mathrm{Mo} / \mathrm{SBA}-15$ & 415 & 120.4 & 57.3 \\
\hline \multicolumn{4}{|l|}{ IWIM } \\
\hline $8 \% \mathrm{Mo} / \mathrm{SBA}-15$ & 322 & 62.2 & 24.0 \\
\hline $3 \%$ Co $8 \%$ Mo/SBA-15 & 222 & 88.4 & 49.1 \\
\hline $3 \%$ Ni 8\% Mo/SBA-15 & 212 & 72.6 & 39.6 \\
\hline $8 \% \mathrm{Mo} / \gamma-\mathrm{Al}_{2} \mathrm{O}_{3}$ & 204 & 22.1 & 11.2 \\
\hline $3 \%$ Co $8 \% \mathrm{Mo} / \gamma-\mathrm{Al}_{2} \mathrm{O}_{3}$ & 138 & 31.8 & 26.8 \\
\hline $3 \% \mathrm{Ni} 8 \% \mathrm{Mo} / \gamma-\mathrm{Al}_{2} \mathrm{O}_{3}$ & 141 & 29.0 & 19.1 \\
\hline
\end{tabular}


atoms in the sulphur edge of $\mathrm{MoS}_{2}$ crystallite which results in high activities even at high promoter loading unlike IWIM-prepared catalysts (table 2). A comparison of Mo, CoMo, NiMo catalysts prepared by PFHS technique using SBA-15 as a support with $\gamma$ $\mathrm{Al}_{2} \mathrm{O}_{3}$-supported Mo, CoMo, NiMo catalysts containing $8 \mathrm{wt} \%$ Mo and $3 \mathrm{wt} \%$ promoters is shown in figure 10. It can be clearly seen that higher activities resulted from PFHS method emphasizes the superiority of the method of preparation. A combination of SBA15 support and PFHS preparation method can achieve three times higher activities due to increased molybdenum dispersion and accommodation of more promoter atoms in highly dispersed state. In the same graph, oxygen uptakes are also plotted which shows similar trend as activities. Since oxygen uptakes are a measure of dispersion of $\mathrm{MoS}_{2}$, it is clear that the superiority of PFHS method lies in its ability to produce small nano particles of $\mathrm{MoS}_{2}$.

\section{Conclusion}

The ordered mesoporous material SBA-15 prepared using triblock polymer is used to prepare Mo, CoMo and NiMo catalysts by PFHS technique, The support and prepared catalysts were characterized by low angle as well as wide angle $\mathrm{XRD}, \mathrm{BJH}$ pore size distribution, BET surface area analysis and XPS. The low angle XRD indicated that the ordered hexagonal mesoporous structure is retained in the $\mathrm{MoS}_{2}$ catalysts too and are conformed by BJH nitrogen adsorption-desorption measurements. The XPS measurements indicated that the dispersion as suggested by $I_{\mathrm{Mo}} / I_{\mathrm{Si}}$ increases up to $10 \mathrm{wt} \%$ Mo in these catalysts. Surface area analysis indicated that $\mathrm{MoS}_{2}$ is dispersed as a monolayer up to $10 \mathrm{wt} \% \mathrm{MoS}_{2}$. Oxygen uptakes and derived small crystallite size $(2.0 \mathrm{~nm})$ indicated that $\mathrm{MoS}_{2}$ is highly dispersed up to $10 \mathrm{wt} \% \mathrm{MoS}_{2}$. Similar results are also inferred from wide angle XRD scans of $\mathrm{MoS}_{2}$ as well as CoMo and NiMo catalysts. All these measurements suggested that this preparation method allows loading of more $\mathrm{MoS}_{2}$ in highly dispersed form which allows creation of more (Ni) Co-Mo-S edge sites resulting in higher activities. A comparison with $\gamma-\mathrm{Al}_{2} \mathrm{O}_{3}$ supported catalysts indicated that this support and preparation method combination increases the activities by about three times.

\section{Acknowledgements}

Authors SG and KS thank the Council of Scientific and Industrial Research, New Delhi, India for the Research fellowship. We also thank ETN Reddy, Chemical Engineering Department, GVP College of Engineering for computer assistance.

\section{References}

1. Topsoe H, Clausen B S and Massoth F E 1996 Hydrotreating science and technology (eds) J R Anderson and M Boudart Vol 11, (Berlin: Springer Verley)

2. Song C 2003 Catal. Today 86211

3. Yokamoto Y, Breyssee M, Murali Dhar G and Song C 2003 Catal. Today 861

4. Murali Dhar G, Srinivas B N, Rana M S, Kumar M and Maity S K 2003 Catal. Today 8645

5. Zdrazil M 2003 Catal. Today 86151

6. Rayo P, Rana M S, Ramirez J, Ancheyta J and AguilarElgue A Z 2008 Catal. Today 130283

7. Stanislaus A, Marafi A and Rana M S 2010 Catal. Today 1531

8. Pena L, Valencia D, Klimova T 2014 Appl. Catal. B: Environ. 147879

9. Valencia D and Klimova T 2013 Appl. Catal. B: Environ. 129137

10. Klimova T E, Valencia D, Arturo J M N and Patricia $\mathrm{H}$ H 2013 J. Catal. 304 29-46

11. Maity S K, Rana M S, Bej S K, Ancheyta J, Murali Dhar G and Prasada Rao T S R 2001 Appl. Catal. A: Gen. 205 215

12. Ng K Y S and Gulari E 1985 J Catal. 9533

13. Maity S K, Rana M S, Srinivas B N, Murali Dhar G, Bej S K and Prasada Rao T S R 2000 J. Mol. Catal. 153121

14. Abotsi G M K and Scaroni A W 1989 Fuel. Proc. Technol. 22107

15. Maity S K, Rana M S, Bej S K, Ancheyta J, Murali Dhar G and Prasada Rao T S R 2001 Catal. Lett. 72115

16. Pophal C, Kameda F, Hoshino K, Yoshinaka S and Segawa K 1997 Catal. Today 3921

17. Vrinat M, Hamon D, Breyssee M and Durand B 1994 Catal. Today 20273

18. Kumar M, Aberuagba F, Gupta J K, Rawat K S, Sharma L D and Murali Dhar G 2004 J. Mol. Catal. A: Chem. 213217

19. Song C and Reddy K M 1996 Appl. Catal. A Gen. 1761

20. Wang A, Wang Y, Kabe T, Chen Y, Ishihara A and Qian W 2001 J. Catal. 19919

21. Sampieri A, Pronier S, Blanchard J, Breyssee M, Brunet S K, Fajerwerg C L and Perot G 2005 Catal. Today 107108537

22. Klimova T, Reyes J, Gutierrez and Lizama L 2008 Appl. Catal. A: Gen. 335159

23. Klimova T, Lizima L, Amezcua J C, Raquero J C, Terres E and Naverreteand Dominguez J 2004 Catal. Today 98 141

24. Soni K, Mouli K G, Dalai A K and Adaye J A 2010 Catal. Lett. 136116

25. Koranyi T I, Vit Z, Podval D G, Ryoo R, Kim H S and Hensen E M J 2008 J. Catal. 253119

26. Muthukumaran G, Garg S, Soni K, Kumar M, Sharma L D, Rama Rao K S and Murali Dhar G 2007 Ind. Eng. Chem. Res. 464747 
27. Garg S, Bhaskar T, Soni K, Muthukumaran G, Muto A, Sakata Y and Murali Dhar G 2008 Chem. Commun. 5310

28. Chiranjeevi T, Kumar P, Rana M S, Murali Dhar G and Prasada Rao T S R 2002 J. Mol. Catal. A: Chem. 181 109

29. Soni K, Rana B S, Sinha AK, Bhaumik A, Nandi M, Kumar M and Murali Dhar G 2009 Appl. Catal. B: Environ. 9055

30. Garg S, Soni K, Muthukumaran G, Kumar M, Gupta J K, Sharma L D and Murali Dhar G 2008 Catal. Today 130302

31. Muthukumaran M, Garg S, Soni K, Kumar M, Sharma L D, Murali Dhar G and Rama Rao K S 2006 Appl. Catal. A: Gen. 305123

32. Amezcua J C, Lizama L, Salcedo C, Puente I, Dominguez J M and Klimova T 2005 Catal. Today 107-108578
33. Rao P K, Prasad V V D N, Rao K S and Chary K V R 1993 J. Catal. 142121

34. Zhao D, Huo Q, Feng J, Chmelka B F and Stucky G D 1998 J. Am. Chem. Soc. 1206024

35. Chary K V R, Kanta Rao P, Prasad V V D N and Somasekhara Rao K 1990 J. Mol. Catal. 63 L21

36. Landau B M V, Vradman L, Wang X and Tetelman L 2005 Micropor. Mesopor. Mater. 78117

37. Rao K S P and Murali Dhar G 1989 J. Catal. 115 277

38. Massoth F E, Murali Dhar G and Shabtai J 1984 J. Catal. 8553

39. Murali Dhar G, Massoth F E and Shabtai J 1984 J. Catal. 8544

40. Topsoe H, Hinnemann B, Norskov J K, Lauritsen J V, Besenbacher F, Hansen P L, Hytoft G, Egeberg R G and Knudsen K G 2005 Catal. Today 10710812 